\title{
The Role and Application of Ion Beam Analysis for Studies of Plasma- Facing Components in Controlled Fusion Devices
}

\author{
M. Rubel ${ }^{\mathrm{a}^{*}}$, P. Petersson ${ }^{\mathrm{a}}$, E. Alves ${ }^{\mathrm{b}}$, S. Brezinsek ${ }^{\mathrm{c}}$, J.P. Coad ${ }^{\mathrm{d}}$, K. Heinola ${ }^{\mathrm{e}}$, M. Mayer ${ }^{\mathrm{f}}$, A. \\ Widdowson ${ }^{\mathrm{d}}$ and JET Contributors** \\ EUROfusion Consortium, JET, Culham Science Centre, Abingdon, OX14 3DB, UK \\ ${ }^{a}$ Fusion Plasma Physics, Royal Institute of Technology (KTH), 10044 Stockholm, Sweden \\ ${ }^{b}$ Instituto Superior Técnico, Universidade de Lisboa, 1049-001 Lisbon, Portugal \\ ${ }^{c}$ Institut für Klima- und Energieforschung, Forschungszentrum Jülich, D-52425 Jülich, Germany \\ ${ }^{d}$ CCFE, Culham Science Centre, Abingdon, OX14 3DB, UK \\ ${ }^{e}$ University of Helsinki, 00014 Helsinki, Finland \\ ${ }^{f}$ Max-Planck-Institut für Plasmaphysik, 85478 Garching, Germany
}

\begin{abstract}
First wall materials in controlled fusion devices undergo serious modification by several physical and chemical processes arising from plasma-wall interactions. Detailed information is required for the assessment of material lifetime and accumulation of hydrogen isotopes in wall materials. The intention of this work is to give a concise overview of key issues in the characterization of plasma-facing materials and components in tokamaks, especially in JET with an ITER-Like Wall. IBA techniques play a particularly prominent role here because of their isotope selectivity in the low-Z range (1-10), high sensitivity and combination of several methods in a single run. The role of ${ }^{3} \mathrm{He}$-based NRA, RBS (standard and micro-size beam) and HIERDA in fuel retention and material migration studies is presented. The use of tracer techniques with rare isotopes (e.g. ${ }^{15} \mathrm{~N}$ ) or marker layers on wall diagnostic components is described. Special instrumentation, development of equipment to enhance research capabilities and issues in handling of contaminated materials are addressed.
\end{abstract}

Keywords: Ion beam analysis, nuclear reaction, controlled fusion, first wall materials, deuterium

*Presenting author: Marek.Rubel@ee.kth.se

**See Appendix to the F. Romanelli et al., Proc. $25^{\text {th }}$ IAEA Fusion Energy Conf. 2014, St Petersburg, Russia 


\section{Introduction}

An integrated science and technology programme is implemented worldwide to provide operation conditions and to construct a power-generating reactor based on controlled thermonuclear fusion of hydrogen isotopes. Taking into account the reaction cross-sections the most efficient fuel for a reactor is a 1:1 mixture of deuterium and tritium: $\mathrm{D}+\mathrm{T} \rightarrow \alpha+\mathrm{n}$ + 17.6 MeV [1]. Strong magnetic fields of several Tesla are used to produce, to confine and to control hot plasmas in toroidal vacuum chambers: either tokamaks [1] or stellarators [2] dependent on the configuration of coils. A tokamak-type configuration has been chosen for ITER (International Thermonuclear Experimental Reactor) being under construction in Cadarache, France. The construction phase is accompanied by a very intense research carried out in several existing fusion devices and also in laboratories and industrial entities engaged in testing and development of materials and components for the plasma-facing wall, diagnostics, various plasma heating systems, magnetic coils, etc.

Material science and engineering are among priority areas of research, because first wall materials in controlled fusion devices undergo serious modification by physical and chemical processes arising from plasma-wall interactions (PWI) [3-6]. The knowledge on material performance under extreme conditions (temperature and radioactivity) is crucial for the development of a power plant reactor. Detailed information is required for the assessment of material lifetime [3,7-9], dust formation [10-16] and accumulation of hydrogen isotopes in wall materials [3,5,6,17-25]. These issues are decisive for the economy and safety of reactor operation. This calls for broad studies on the behaviour of wall materials under impact of hot plasmas. There is no ideal element, alloy, composite or compound as a constituent of a plasma-facing wall. For many years carbon (in the form of fiber composites, CFC), beryllium and tungsten have been considered and tested as candidates in tokamaks and in material research laboratories. The use of all three was planned for different areas of the ITER wall, dependent on the power loads to be deposited. Carbon - the most relevant for power handling and resilient to thermal shocks - has been eliminated from the list because of its affinity to hydrogen isotopes (I) towards the formation of volatile $\mathrm{C}_{\mathrm{x}} \mathrm{I}_{\mathrm{y}}$ compounds, their transport and re-deposition. As a consequence, it would lead to unacceptable level of radioactive tritium inventory in the reactor $[3,26,27]$. The decision on the final material choice was preceded by the first large-scale test of the simultaneous use of beryllium and tungsten in the JET tokamak with the ITER-Like Wall (JET-ILW): Be in the main chamber wall and W in the divertor [28- 
32]. A significant reduction of the fuel inventory has been observed in comparison to the operation with a carbon wall (JET-C).

Knowledge and understanding of material behaviour requires broad experimental programme in fusion devices and thorough material analyses before and after exposure to plasma. The aim of this paper is to provide an overview of surface analysis, especially ion beam techniques, in the determination of wall material modification in controlled fusion. Particular emphasis is given to the research programme at JET-ILW. The paper is structured along the points: "what" is to be analysed and "why", and then "how" the analyses are carried out. This also includes the use of special diagnostic instrumentation, tracer techniques and development of equipment for efficient analysis.

\section{Objectives and objects of analysis}

Toroidal chambers of tokamaks belong to largest ever constructed and operated vacuum vessels. JET is currently the largest world's tokamak. The volume of its vacuum vessel exceeds $100 \mathrm{~m}^{3}$ (ITER will be approximately 8 times larger) and the total wall area is several hundred $\mathrm{m}^{2}$. The wall structure is very diverse, as exemplified in Figure 1 on which a toroidal view into the JET-ILW is presented. The entire vessel is composed of the main chamber and - at the bottom - the divertor where the greatest power loads are deposited. The main plasmafacing components (PFC) are outer poloidal limiters (OPL), inner wall guard limiters (IWGL), upper dump plates (UDP), all three types made of Be, and the divertor (DIV) plates made either of bulk tungsten or W-coated CFC. Other parts are inner wall cladding (IWC, beryllium coated Inconel) and various types of antennae (AN) for auxiliary plasma heating. On the left there is a remotely handled ( $\mathrm{RH}$ ) robotic arm for all in-vessel operations such as installation, exchange of PFC and diagnostics in the environment containing beryllium and tritium, the latter originates from the fusion reaction $\mathrm{D}+\mathrm{D} \rightarrow \mathrm{H}+\mathrm{T}+4.03 \mathrm{MeV}$ and the residual amount after the full D-T operation in 1998 [17,19,27].

The ultimate aim of the analysis is to obtain as complete as possible pattern of material modification and migration arising from erosion-deposition phenomena. It is done by addressing a number of questions: (i) where are the erosion zones; (ii) where is the eroded material deposited; (iii) how are the materials modified; (iv) how much fuel is retained in the wall and, eventually, (v) what is the impact of wall materials on material migration? The aim can be achieved only by studying a set of PFC representative for various areas in the device: 
tiles from at least one full poloidal cross-section of the divertor and a number of limiter tiles and dump plates. To obtain proper insight into material migration on the main chamber wall (behind the limiters) and in remote areas of the divertor, i.e. zones shadowed from the direct plasma line-of-sight where the greatest fuel inventory occurred in JET with carbon walls $[17,19,23]$. To deal with such points a large number of erosion-deposition diagnostic tools are used at JET in many locations schematically marked in Figure 1. Marker tiles (filled rectangles and ovals) are installed in all important locations in the limiter arrays and in the divertor. Wall probes (WP, light filled ovals and circle) such as rotating collectors, inserts in IWC, quartz microbalance (QMB), louvre clips and units with mirrors for the First Mirror Test (FMT) at JET for ITER are in two positions in the main chamber and in shadowed areas in the divertor. All details regarding marker tiles and wall probes in JET-ILW have been described earlier [33].

In detailed analysis of wall materials the interest is in the determination of all species which may be present in the reactor $\mathrm{H}, \mathrm{D}, \mathrm{T},{ }^{4} \mathrm{He},{ }^{6} \mathrm{Li},{ }^{7} \mathrm{Li},{ }^{9} \mathrm{Be},{ }^{10} \mathrm{Be},{ }^{10} \mathrm{~B},{ }^{11} \mathrm{~B},{ }^{12} \mathrm{C},{ }^{13} \mathrm{C},{ }^{14} \mathrm{C},{ }^{14} \mathrm{~N},{ }^{15} \mathrm{~N}$, ${ }^{16} \mathrm{O},{ }^{18} \mathrm{O},{ }^{19} \mathrm{~F},{ }^{20} \mathrm{Ne},{ }^{21} \mathrm{Ne},{ }^{22} \mathrm{Ne}, \mathrm{Si}, \mathrm{Cr}, \mathrm{Fe}, \mathrm{Ni}, \mathrm{Mo}, \mathrm{W}$, Re. These are hydrogen fuel isotopes, wall constituents (C, Be, W, Inconel components, Mo) or those used in plasma diagnosis systems and/or for wall conditioning ( $\mathrm{He}, \mathrm{B}, \mathrm{C}, \mathrm{Si}$ ), common impurities (C, O), gases seeded for plasma edge cooling ( $\mathrm{N}, \mathrm{Ne}$ ) and tracers of material migration introduced deliberately to the studied system in minute quantities. The latter category comprises rare isotopes C-13 [23,34-36], N-15 [37,38], O-18 [39] injected in the form of gases or as solids ${ }^{9} \mathrm{Be}$ [40] or Re [36]. The presence of ${ }^{14} \mathrm{C}$ has also been monitored [36]. The main point is the need to characterize qualitatively and quantitatively a mixture of low-Z isotopes and - on many occasions - to resolve a spectrum in which there are simultaneously many species listed above.

\section{Material analysis: Methods and laboratory equipment}

Analyses of materials from different devices have been carried out regularly since eighties when several medium- and large size devices came to operation: ASDEX, TFTR, TEXTOR, JET and JT-60. More than forty different material research methods have been used over the years for analysis of PFC and probes exposed to plasma in fusion devices and simulators of PWI. A list of the most important methods comprises high-resolution microscopy and techniques providing data on hydrogen isotopes: thermal desorption spectroscopy (TDS), secondary ion mass spectrometry (SIMS), liquid scintillography and IBA methods. The latter group (i.e. IBA) plays a prominent role as the most versatile set of tools: nuclear reaction 
analysis (NRA), elastic recoil detection analysis (ERDA) including high energy heavy ion variants, Rutherford backscattering spectroscopy (RBS), enhanced proton scattering (EPS), particle-induced X-ray emission (PIXE), and accelerator mass spectrometry (AMS). The importance of IBA in PFC studies was recognized in seventies [41,42]. Since then the area has been growing to become a very well established field of research, but still meeting new challenges related to the operation with both very low-Z and very high-Z materials. NRA based on ${ }^{3} \mathrm{He}$-induced process has a particular place in the catalogue of methods as the most efficient approach to the quantification and depth profiling of deuterium [43]. Studies on the cross-sections in a wide energy range of a He-3 beam and on the determination of analysis limits in different materials are still carried out to perfect the analytical outcome [44-47]. Nuclear reactivity of that helium isotope is also very broadly used to quantify simultaneously D, Be, C and other light nuclei [17,18,22,23].

There are several specific issues in studies of material from tokamaks, especially in the case of JET where one deals with the contaminated specimens: retrieval from the torus, handling and sampling. Wall tiles and probes can be retrieved and replaced by a new set only during major shut-downs with all in-vessel actions done by remotely controlled robots. This is followed by the transfer of items to the Beryllium Handling Facility (BeHF) where all operations (e.g. dismantling from the divertor carriers, packaging) are performed in glove boxes by personnel wearing pressurized suits, as shown in Fig. 2.

There are two major categories of items retrieved: those which have spares and can be replaced and those without spares. The cost of wall tiles is high and, therefore, some items selected for analyses are unique, i.e. there are no spares to be used for replacement. Tiles of this category are to be analysed ex-situ and returned to JET for re-assembly during the same shut-down. This means no sampling by any means of sectioning can be performed. It also implies a need for robust long-travel linear manipulators, 150-200 mm diameter loading ports and large-volume chambers at surface analysis stations because tiles are big, e.g. W-coated CFC divertor tile 5x16x25 cm, mass over $2 \mathrm{~kg}$. Images in Figure 3 show four types of tiles used in JET-ILW.

Tiles which have spares are sectioned to provide samples for different types of surface and bulk analyses. W-coated CFC tiles are “cored” in the form of cylinders (8 or $18 \mathrm{~mm}$ in diameter) [48], while beryllium, tungsten and Inconel are to be sawn [49] under strict temperature control during that procedure. 
There is a network of European laboratories involved in studies of material retrieved from JET. This includes six stations (locations below are listed in alphabetic order) where IBA of materials from JET-ILW is carried out: Athens, Garching, Helsinki, Lisbon, Uppsala, and Zagreb. Each laboratory has capability of handling contaminated materials and has several beam lines. Images in Figure 4 (a) and (b) show Be-compatible apparatus equipped with glove boxes in Lisbon and in Garching, respectively. A scheme of the beam lines and associated methods at the Tandem Laboratory in Uppsala is in Figure 5; all lines are used for studies of materials from JET. A wide spectrum of methods including micro-beam systems (Athens, Lisbon, Uppsala, Zagreb) and heavy ion ERDA gives comprehensive insight into the material modification under plasma impact. High resolution and precise mapping and depth profiling can be performed and, by this, erosion-deposition scenario and history can be inferred.

\section{Application of IBA in studies of JET-ILW components: Examples}

\subsection{Erosion and deposition in the JET-ILW inner divertor}

Optimization of the divertor geometry has been one of the key scientific missions of JET. Therefore, systematic studies of the erosion-deposition pattern have been carried out for all consecutive JET divertors in order to determine material transport and fuel retention [17-19]. Figure 6 shows a cross-section of the JET-ILW divertor. Two important features are marked: (a) the most representative strike point positions (on Tiles 3 and 5) during the first phase of operation with all metal walls [31]; (b) the so-called S-coordinate which denotes in mm the poloidal position on the divertor tiles.

A set of tiles from the entire poloidal cross-section of the divertor have been studied with IBA [48,50-52]. Graphs in Figure 7 show detailed patterns for all analysed species along the poloidal direction on Tile 1 from the top of the inner divertor, the tile is encircled in Fig. 6. This particular W-coated CFC tile is additionally coated with a marker coatings: $4 \mu \mathrm{m} \mathrm{Mo}$ interlayer covered by $4 \mu \mathrm{m}$ of $\mathrm{W}$. One may notice that over the entire tile the feature of Mo after the exposure is the same as on the initial surface. There are differences in the distribution of $\mathrm{W}$ indicating both the deposition of that species on the sloping part of Tile 1 (S range 225 $300 \mathrm{~mm}$ ) and erosion in the vertical part above $350 \mathrm{~mm}$. The deposition is related to tungsten erosion from some $\mathrm{W}$-coated CFC tiles located in the main, i.e. protected area on inner wall exposed to neutral beam injection (shine through region) and some other parts that may be affected by high heat loads. The erosion area coincides with the position of the strike point occasionally placed on the vertical part of Tile 1, as documented in [52]. The presence of 
beryllium, deuterium and also of carbon clearly prove deposition on the horizontal part (socalled apron) of Tile 1. It is the main deposition area in JET-ILW, as presented in detail in [48,51,52]. Beryllium layer thickness reaches $15 \mu \mathrm{m}$ as measured both by hydrogen beam EPS and microscopy-based cross-sectional analysis of deposits on the tiles [48]. Oxygen detected in the layer may originate from plasma impurities related to leaks, but also from surface oxidation of beryllium deposit when the tiles are exposed to air after the retrieval from the JET vessel.

In summary, the detailed analyses performed for a poloidal set of tiles has revealed a complete erosion-deposition pattern in the divertor. It has clearly shown a much lower deuterium inventory in JET-ILW in comparison to JET-C. Deuterium retention determined with IBA and normalized with respect to the operation time has been decreased by a factor of 10-15 which is full agreement with the decrease of carbon fluxes determined by optical spectroscopy techniques in the divertor [31,32,57].

\subsection{Deposition in castellated limiters}

All PFC in ITER will be castellated (“chocolate” bar structure with 12-16 mm deep and 0.6 mm wide grooves cut every $10-20 \mathrm{~mm}$ on a tile) to ensure the thermo-mechanical durability and integrity of materials under high heat flux loads. However, gaps separating PFC and grooves of the castellation may act as traps for fuel and eroded material transported to those areas which are shadowed from the direct plasma impact. Comprehensive studies were performed on castellated Be limiter and divertor tiles used at JET-C [53-55] or on high-Z castellation tested in other machines [56] with carbon walls.

Operation of JET-ILW has allowed for a full-scale test. An outer poloidal limiter tile, the one shown in Figure 3(b), was sawn to expose surfaces located in the castellated grooves. An image in Figure 8 (a) shows a deposited layer formed in the upper part of the groove. Plots in Figure 8 (b) obtained with micro-beam NRA and PIXE document the distribution of deuterium and metals. The $\mathrm{D}$ signal was measured via the $\mathrm{D}\left({ }^{3} \mathrm{He}, \mathrm{p}\right)^{4} \mathrm{He}$ reaction using a 1500 $\mu \mathrm{m}$ annular detector. For the different metals PIXE was used with a $3 \mathrm{~mm}$ thick Si(Li) detector cooled with liquid nitrogen. Both measurements were done simultaneously with a 3 $\mathrm{MeV}^{3} \mathrm{He}$ beam. The beam was scanned over an area of about 2x2 mm² (limited by the size of the hole in the annular detector) and the deposition profile in the groove was made by projecting the scanned area on axis perpendicular to the surface sample effectively creating a line scan perpendicular to the surface. To go deeper than $2 \mathrm{~mm}$ several scans were made after 
movements by a known distance and combined then during the analysis. For the size calibration fine $\mathrm{Cu}$ grids of known dimensions was used. Surfaces in several grooves have been studied. This careful, though very time-consuming, analytical procedure reveals shallow deposition of deuterium and metals (mainly nickel) extended 1-2 mm deep into the groove. The deuterium profile does not decay monotonically from the tile surface but it peaks at round $0.5 \mathrm{~mm}$ deep into the gap. It is related to the thermal release of species deposited closer to the entrance. The maximum amount does not exceed $1 \times 10^{18} \mathrm{~cm}^{-2}$. Assuming symmetry of the retention in the castellation an integrated amount in all outer poloidal and inner wall guard limiters is assessed to be in the range $7-10 \times 10^{21} \mathrm{D}$ atoms. This content is about 10 times lower than the amount determined on the plasma-facing surfaces of limiters: $10 \times 10^{22} \mathrm{D}$ atoms [57]. The result from JET-ILW allows for some optimism regarding fuel retention inside the castellated structures in ITER.

\subsection{Deposition in shadowed areas of the divertor}

Deposition in the remote areas shadowed from the direct plasma line-of-sight could be determined on surfaces of mirrors exposed for the First Mirror Test at JET for ITER [58,59]. A set of mirrors made of polycrystalline molybdenum (pure or Rh-coated) were exposed during the entire first campaign of JET-ILW. Heavy ion ERDA (HIERDA) with $36 \mathrm{MeV}$ ${ }^{127} \mathrm{I}^{8+}$ ions was used for the quantification and depth profiling of light and heavy nuclei in the surface region of up to $200 \mathrm{~nm}$. Figure 9 (a) shows a HIERDA spectrum for an Rh-coated mirror and plots in Figure 9 (b) are detailed depth profiles. Features of hydrogen isotopes $(\mathrm{H}$, D), ${ }^{9} \mathrm{Be},{ }^{12} \mathrm{C},{ }^{14} \mathrm{~N}$ and ${ }^{16} \mathrm{O}$ clearly identified. There are also traces of tungsten (W) and Inconel components (Ni, Fe, $\mathrm{Cr}$ ). The shape of all those lines clearly indicates the presence of a deposited surface layer on rhodium. Atomic density $\left(10^{15}\right.$ atoms $\left./ \mathrm{cm}^{2} / \mathrm{nm}\right)$ of eight species is given. In this figure, $\mathrm{Ni}$, as a dominant element in Inconel alloy, indicates a group of Inconel metals. From these data one infers the absolute content of elements (isotopes for light nuclei) and the structure of the layer, and - from this - a history of deposition which reflects the history of plasma operation. The co-deposit thickness is around $100 \mathrm{~nm}$, but the interface where features of Rh and other species are mixed is fairly broad, approximately $50 \mathrm{~nm}$. This width can be associated with three reasons: the HIERDA beam spot area, material mixing and even minor surface roughness. The major components are beryllium, carbon, nitrogen, oxygen and deuterium, but their profiles are different. The content of beryllium is high and fairly uniform. There are two maxima of oxygen: at the surface and at the interface what is most 
probably associated with its adsorption on the exposed surface and on the original mirror when it was installed in JET. The region from $25 \mathrm{~nm}$ to $75 \mathrm{~nm}$ informs about the oxygen impurity deposition during plasma operation. This resulted in the oxygen content 5-7 times lower than at maxima. Carbon is found predominantly at the depth of $60-100 \mathrm{~nm}$, thus corresponding to the initial period of the JET-ILW operation. At the smaller depth the content decreased by a factor of about seven what agrees with spectroscopy measurements of $\mathrm{C}$ impurity species [31]. The concentration of nitrogen increases towards the deposit surface thus reflecting the history of the $\mathrm{H}$-mode operation associated with $\mathrm{N}_{2}$ impurity seeding predominantly done during the second half of the operational campaign. The profile of deuterium shows some variations, but its concentration is in general fairly low. However, the most striking feature is the presence of tungsten in the deposit and a "wavy" structure of the $\mathrm{W}$ feature. Its content is low but rising with a sharp increase at the surface of the deposit corresponding to the increase of heating power in JET operation. The increase of the W signal is also accompanied by the appearance of nickel what may indicate its erosion from the antennae grills or even damage to the beryllium coating on Inconel cladding tiles.

\subsection{Tracer techniques and the use of HIERDA}

Tracer techniques are widely used in science and industry to determine for instance flows, reaction rates and mechanisms, i.e. to reveal decisive steps in studied processes. In the field of PFC studies the term “tracer” denotes species introduced on purpose to plasma edge in order to determine material migration and its impact on fuel retention. It is done either by puffing exotic (e.g. $\mathrm{MoF}_{6}, \mathrm{WF}_{6}$ ) or isotope-labeled gases, by ablating tracer material using lasers or as described in Paragraph 4.1 - by exposing marker tiles. The selection and application of tracers requires availability of a tracer, its affordable cost, proper surface probes placed in several locations and relevant analytical methods in order to obtain a deposition pattern. In the case of low-Z isotope tracer gases (e.g. ${ }^{13} \mathrm{CH}_{4},{ }^{15} \mathrm{~N}_{2},{ }^{18} \mathrm{O}_{2}$ ) the analysis technique must be capable of the quantification of respective isotopes in a mixture of species from hydrogen to neon. Experiments are usually followed by the immediate retrieval of the exposed materials; therefore, sensitive analysis of the surface layer is crucial. The required capabilities are provided by HIERDA, which has been successfully used in the examination of probes and tiles after complex tracer experiments involving simultaneous use of both low-Z and high- $\mathrm{Z}$ tracers: ${ }^{13} \mathrm{C},{ }^{15} \mathrm{~N}$ and $\mathrm{WF}_{6}[60,61]$.

Nitrogen is used in fusion devices for plasma edge cooling. A fraction of the injected gas is retained in the wall. The question is: how much is retained? Because tiles retrieved from the 
torus are transported by air it is difficult to assess the in-vessel retention. Tracer experiments with pure ${ }^{15} \mathrm{~N}_{2}$ injection allow to distinguish it on surfaces from the air nitrogen and, by this, they inform about the retention. After developing the experimental procedure in TEXTOR and ASDEX-Upgrade [60-63] a minute amount of ${ }^{15} \mathrm{~N}_{2}$ marker was puffed from a single gas inlet into the JET divertor. Despite continuation of the plasma operation for another 151 pulses (approx. $330 \mathrm{~s}$ ) the isotope was detected in a co-deposit on a quartz micro-balance device located in the outer divertor [51]. This clearly indicates a long-term retention of nitrogen in the torus and, it demonstrates advantages of using HIERDA in studies of probes exposed to tokamak plasma or tested in simulators of PWI [64]. Though the technique is best suited to probes with smooth surfaces it also yields relative results, i.e. concentration ratio of species in co-deposits on tiles $[61,65]$. The range of applications in studies of PFC will still be extended and enhanced with new detectors based on the gas ionization chambers [66].

\section{Concluding remarks}

High sensitivity, selectivity together with versatility of IBA method make the surface analysis stations the most effective „tool-box“ in studies of wall materials from fusion experiments. They provide high speed of probing over large surfaces to produce a map of erosion and deposition zones. In most cases a standard beam-size (i.e. 0.5-1 mm in diameter) is sufficient in NRA, PIXE, RBS and EPS, as demonstrated in the range of applications described above. Micro-beam measurements address very specific points such deposition in the castellation (Paragraph 4.2) and macroscopically non-uniform distribution of species in deposits [37,67] because of the surface roughness. Roughness of the plasma-exposed surfaces is unavoidable and it must be carefully taken into account in the evaluation of analytical results $[68,69]$. In this sense, further improvements in the beam size and resolution to the nano-scale, crucial in many disciplines [70,71], may not be here of the greatest importance taking into both the initial and plasma-induced roughness.

The major challenges in analysis of PFC by ion beams and also other material research techniques are related to a large number and diversity of components retrieved for ex-situ studies from JET during consecutive experimental campaigns. The data on fuel retention and material mixing are crucial for ITER. IBA is indispensable and unique in the determination of deuterium retention (lateral and depth profiling) to provide basis for predicting tritium inventory. It should be stressed that the community is fully aware of ion-induced detrapping connected with the ${ }^{3}$ He-D nuclear reaction or HIERDA [72-75]. The emphasis in current and 
future studies is on the determination of fuel inventory in tungsten and W-Be-C-O-N mixed materials.

\section{Acknowledgement}

This work has been carried out within the framework of the EUROfusion Consortium and has received funding from the Euratom research and training programme 2014-2018 under grant agreement No 633053. The views and opinions expressed herein do not necessarily reflect those of the European Commission. The work has been partly funded by the Swedish Research Council (VR) through contract no. 621-2009-4138.

\section{References}

[1] J. Wesson, Tokamaks, Oxford University Press, $3^{\text {rd }}$ Edition, 2004

[2] M. Wakatani. Stellarator and heliotron devices. Oxford University Press, 1998.

[3] G. Federici et al., Plasma - material interactions in current tokamaks and their implication for next step fusion reactors, Nucl. Fusion 41 (2001) 1967-2137.

[4] W.O. Hofer and J. Roth (Eds), Physical Processes of the Interaction of Fusion Plasmas with Solids, Academic Press, New York, 1996.

[5] V. Philipps, P. Wienhold, A. Kirschner and M. Rubel, Erosion and deposition of wall materials in controlled fusion devices, Vacuum 70 (2002) 399-408.

[6] J. Roth et al., Recent analysis of key plasma-wall interactions for ITER, J. Nucl. Mater. 390-391 (2009) 1-9.

[7] A. Loarte, Implications of the Use of Carbon-Based Plasma Facing Components in Next Step Fusion Devices”, Phys. Scr. T111 (2004) 13.

[8] J. Linke, "Plasma Facing Materials and Components Future Fusion Devices:

Development, Characterization and Performance under Fusion Specific Loading Conditions”, Phys. Scr. T123 (2006) 45.

[9] J. Linke et al., Material degradation and particle formation under transient thermal loads, J. Nucl. Mater 438 (2013) 1102-1106. 
[10] J. Winter and G. Gebauer, Dust in Magnetic Confinement Devices and its Impact on Plasma Operation, J. Nucl. Mater. 266-269 (1999) 228.

[11] M. Rubel et al., Dust Particles in Controlled Fusion Devices, Nucl. Fusion 41 (2001) 1087.

[12] V. Rohde et al., Dust Investigations at ASDEX Upgrade, Phys. Scr. T138 (2009) 014024.

[13] D. Ivanova et al., Survey of Dust Formed in the TEXTOR Tokamak: Structure and Fuel Retention, Phys. Scr.T138 (2009) 014025.

[14] M. Balden et al., Collection strategy, inner morphology and size distribution of dust particles in ASDEX Upgrade, Nucl. Fusion 54 (2014) 073010.

[15] A. Baron-Wiechec et al., First dust study in JET with the ITER-Like Wall: Sampling, analysis and classification, Nucl. Fusion, in press.

[16] B. Braams, Characterization of Size, Composition and Origins of Dust in Fusion Devices, IAEA 2012, http://www-nds.iaea.org/reports-new/indc-reports

[17] J.P. Coad et al. Erosion/deposition issues at JET, J. Nucl. Mater. 290-293 (2001) 224.

[18] J. P. Coad et al., The Amount and Distribution of Deuterium Retained in the JET Divertor after the C and Be Phases, J. Nucl. Mater. 241-243 (1997) 408.

[19] M. Rubel et al., Beryllium and Carbon Films in JET following D-T Operation, J. Nucl. Mater. 313-316 (2003) 323.

[20] M. Mayer et al, Hydrogen inventories in nuclear fusion devices, J. Nucl. Mater. 290293 (2001) 381.

[21] M. Rubel, P. Wienhold and D. Hildebrandt, Fuel accumulation in co-deposited layers on plasma-facing-components, J. Nucl. Mater. 290-293 (2001) 473.1

[22] M. Rubel, J.P. Coad, J. Likonen and V. Philipps, Analysis of fuel retention in plasmafacing components from controlled fusion devices, Nucl. Instr. and Meth. B 267 (2009) 711-717.

[23] J.P. Coad et al, Overview of material re-deposition and fuel retention studies at JET with the Gas Box Divertor, Nucl. Fusion 46 (2006) 350-366.

[24] B. Pegourie et al, Deuterium inventory in Tore Supra, J. Nucl. Mater. 438 (2013) S120. 
[25] M. Mayer et al., The deuterium inventory in ASDEX Upgrade, Nucl. Fusion 47 (2007) 1607.

[26] Progress in the ITER Physics Basis, Nucl. Fusion 47 (2007), (also: www.iter.org).

[27] D. Stork (Ed.), Technical Aspects of Deuterium-Tritium Operation at JET, (special issue) Fusion Eng. Des. 47 (1999).

[28] G.F. Matthews et al., Overview of the ITER-Like Wall project, Phys. Scr. T128 (2007) 138-143.

[29] G.F. Matthews et al., Current status of the ITER-Like Wall project, Phys. Scr. T138 (2009) 014030.

[30] G.F. Matthews et al., The JET ITER-Like Wall - Status and Experimental programme, Phys. Scr. T145 (2011) 014001.

[31] G.F. Matthews, Plasma operation with an all metal first wall: Comparison of an ITERlike wall with a carbon wall in JET, J. Nucl. Mater. 438 (2013) S1.

[32] S. Brezinsek et al, Beryllium migration in JET ITER-like wall plasmas, Nucl. Fusion 55 (2015) 063021.

[33] M. Rubel et al., Overview of erosion-deposition diagnostic tools for the ITER-like wall in the JET tokamak, J. Nucl. Mater. 438 (2013) S1204-1208.

[34] M. Rubel, P. Wienhold and D. Hildebrandt, Ion beam analysis methods in studies of plasma-facing materials in controlled fusion devices, Vacuum 70 (2003) 423-428.

[35] M. Rubel, J.P. Coad and D. Hole, Accelerator-based ion beam analysis of fusion reactor material, Vacuum 78 (2005) 225-261.

[36] M. Rubel et al., Overview of tracer techniques in studies of material erosion, redeposition and fuel inventory in tokamaks, J. Nucl. Mater. 329-333 (2004) 795-799.

[37] P. Petersson et al., Nuclear reaction and heavy ion ERD analysis of wall materials from controlled fusion devices: deuterium and nitrogen-15 studies, Nucl. Instrum. Meth. B273 (2012) 113-117.

[38] P. Petersson et al., Transport and retention studies in tokamaks using ${ }^{15} \mathrm{~N}$ tracer gas, Phys. Scr. T159 (2014) 014042.

[39] A. Garcia-Carrasco et al., Impact of ion cyclotron wall conditioning on plasma-facing components, Phys. Scr. T159 (2014) 014017.

[40] I. Bykov et al., These Proceedings 
[41] D. Fink et al., Application of (n,p) and (n, a) reactions and backscattering technique to fusion reactor materials, archeometry and nuclear spectroscopy (n-Be, n-6Li), Nucl. Instr. Meth 168 (1980) 453-457.

[42] B.L. Doyle et al., Saturation and isotope replacement of deuterium in low-Z materials, J. Nucl. Mater. 93-94 (1980) 551-557.

[43] W. Möller and F. Besenbacher, A note on the ${ }^{3} \mathrm{He}+\mathrm{D}$ cross-sections, Nucl. Instr. Meth. 168 (1980) 111-114.

[44] M. Mayer et al., Quantitative depth profiling of deuterium up to very large depths, Nucl. Instr. and Meth. B 267 (2009) 506-512.

[45] B. Wielunska et al, Experimental determination of cross section data for the $\mathrm{D}\left({ }^{3} \mathrm{He}, \mathrm{p}\right)^{4} \mathrm{He}$ nuclear reaction from 0.25 to $6 \mathrm{MeV}$, These Proceedings.

[46] T. Schwarz-Selinger et al., Limits of deuterium depth profiling in tungsten with the $\mathrm{D}\left({ }^{3} \mathrm{He}, \mathrm{p}\right)^{4} \mathrm{He}$ nuclear reaction, These Proceedings.

[47] U. von Toussaint et al., Optimizing Nuclear Reaction Analysis (NRA) using Bayesian Experimental Design, AIP Proceedings 1073 (2008) 348-358.

[48] J. Likonen et al., Analysis strategy for the ITER-like Wall at JET, Phys. Scr. T159 (2014) 014016.

[49] A. Widdowson et al., Experience in handling beryllium, tritium and activated components from JET ITER-Like Wall, Proc. 15th Int. Conf. on Plasma-Facing Materials and Components (PFMC-15), France, May, 2015.

[50] J.P. Coad et al., Surface analysis of tiles and samples exposed to the first JET campaigns with the ITER-like wall, Phys. Scr. T159 (2014) 014012.

[51] P. Petersson et al., Co-deposited layers in the divertor region of JET-ILW, J. Nucl. Mater. 463 (2015) 814.

[52] M. Mayer, Erosion and deposition in the JET divertor during the first ILW campaign, Proc. 15th Int. Conf. on Plasma-Facing Materials and Components (PFMC-15), France, May, 2015.

[53] M. Rubel et al., Fuel Inventory and Co-Deposition in Grooves and Gaps of Divertor and Limiter Structures, Phys. Scr. T111 (2004) 112-117.

[54] M. Rubel, P. Coad and R.A. Pitts, Overview of co-deposition and fuel inventory in castellated divertor structures at JET, J. Nucl. Mater, 367-370 (2007) 1432-1437. 
[55] M. Rubel, J.P. Coad and D. Hole, Overview of long-term fuel inventory and codeposition in castellated beryllium limiters at JET, J. Nucl. Mater. 386-388 (2009) 729732.

[56] A. Litnovsky et al., Overview of material migration and mixing, fuel retention and cleaning of ITER-like castellated structures in TEXTOR, J. Nucl. Mater. 415 (2011) S289-S292.

[57] K. Heinola et al., Long term fuel retention in JET ITER-Like Wall, Proc. 15th Int. Conf. on Plasma-Facing Materials and Components (PFMC-15), France, May, 2015.

[58] M. Rubel et al., Mirror test for International Thermonuclear Experimental Reactor at the JET tokamak: An overview of the program, Rev. Sci. Instrum. 77 (2006) 063501.

[59] D. Ivanova et al., An overview of the Comprehensive First Mirrors Test in JET with ITER-Like Wall , Phys. Scr. T159 (2014) 014011.

[60] P. Petersson et al., Nuclear reaction and heavy ion ERD analysis of wall materials from controlled fusion devices: Deuterium and nitrogen-15 studies, Nucl. Instrum. Meth. B273 (2012) 113-117.

[61] M. Rubel et al., Tungsten migration studies by controlled injection of volatile compounds, J. Nucl. Mater. 438 (2013) S170-174.

[62] P. Petersson et al., Injection of nitrogen-15 tracer into ASDEX Upgrade: new technique in material migrations studies, J. Nucl. Mater. 438 (2013) S616-619.

[63] P. Petersson et al., Overview of nitrogen-15 application as a tracer gas for material migration and retention studies in tokamaks, Phys. Scr. T159 (2014) 014042.

[64] P. Ström et al., Relevance of ERDA and RBS for tungsten tracing in wall materials from fusion experiments, These Proceedings.

[65] P. Ström et al., Characterization of layers formed on plasma-facing components in controlled fusion devices: the role of HIERDA, Vacuum, in press.

[66] P. Ström et al., Design of a gas ionization chamber for elastic recoil detection analysis of fusion reactor wall materials, Proc.12th Kudowa Summer School : Towards Fusion Energy, (2014) 71-74, ISSN: 2083-5876.

[67] H. Bergsåker et al., Microscopically non-uniform deposition of deuterium retention in the JET with ITER-like wall, J. Nucl. Mater. 463 (2015) 956-960.

[68] M. Mayer, Ion beam analysis of rough thin films, Nucl. Instr. Meth. B194 (2002) 177.

[69] M. Mayer, Ion beam analysis of laterally inhomogeneous materials, These Proceedings. 
[70] A. Vantomme, 50 years of ion channeling in materials science - where do we go next? These Proceedings

[71] R. Heller et al., Ion beam analysis in the helium ion microscope, These Proceedings.

[72] J. Roth et al., Trapping, detrapping and replacement of keV hydrogen implanted into graphite, J. Nucl. Mater. 93-94 (1980) 601-607.

[73] B.M.U. Scherzer et al., Trapping and release of D from "saturated" implants in graphite, J. Nucl. Mater 176-177 (1990) 208-212

[74] K. Morita and Y. Hasebe, A new model for the release of hydrogen isotopes from graphite, J. Nucl. Mater 176-177 (1990) 213-217.

[75] M. Rubel, H. Bergsåker and P. Wienhold, Ion-induced detrapping of deuterium from co-deposits by high energy helium bombardment, J. Nucl. Mater. 241-243 (1997) 10261030. 


\section{Figure captions}

\section{Figure 1}

Toroidal view into the JET vacuum vessel with marked distribution of wall materials and erosion - deposition diagnostics: marker tiles (filled rectangles) and wall probes (light filled ovals and circles).

\section{Figure 2}

Operation in the Beryllium Handling Facility at the Culham Science Centre.

\section{Figure 3}

PFC tiles from JET: (a) W-coated CFC from the JET divertor, Tile 4 bottom of the inner divertor; (b) segment on the castellated Be tile - outer poloidal limiter; (c) Be-coated Inconel inner wall cladding; (d) bulk tungsten divertor Tile 5 with standard and marker lamellae, marked with $S$ and $M$, respectively.

\section{Figure 4}

Beryllium and tritium compatible surface analysis stations at IBA laboratories: (a) Institute of Superior Techniques, Lisbon, Portugal; (b) Max-Planck Institute of Plasma Physics, Garching, Germany.

\section{Figure 5}

Beam lines and IBA stations at the $5 \mathrm{MeV}$ Tandem Laboratory, Uppsala University, Sweden.

\section{Figure 6}

Cross-section of the JET divertor with the S-coordinate marking the poloidal position of the tiles. Tile 1 is encircled.

\section{Figure 7}

Erosion-deposition pattern obtained with NRA and RBS for on Tile 1 in the inner divertor of JET-ILW after the campaign 2011-2012.

\section{Figure 8}

Castellated beryllium limiters: (a) deposit inside the castellation; (b) micro-beam pattern of deuterium and metals deposition inside the castellation. 


\section{Figure 9}

Surface composition of the mirror exposed in the inner divertor: (a) HIERDA spectrum and (b) depth profiles of co-deposited elements on the Rh-coated mirror. 


\section{Figure 1}

Toroidal view into the JET vacuum vessel with marked distribution of wall materials and erosion - deposition diagnostics: marker tiles (filled rectangles) and wall probes (light filled ovals and circles).

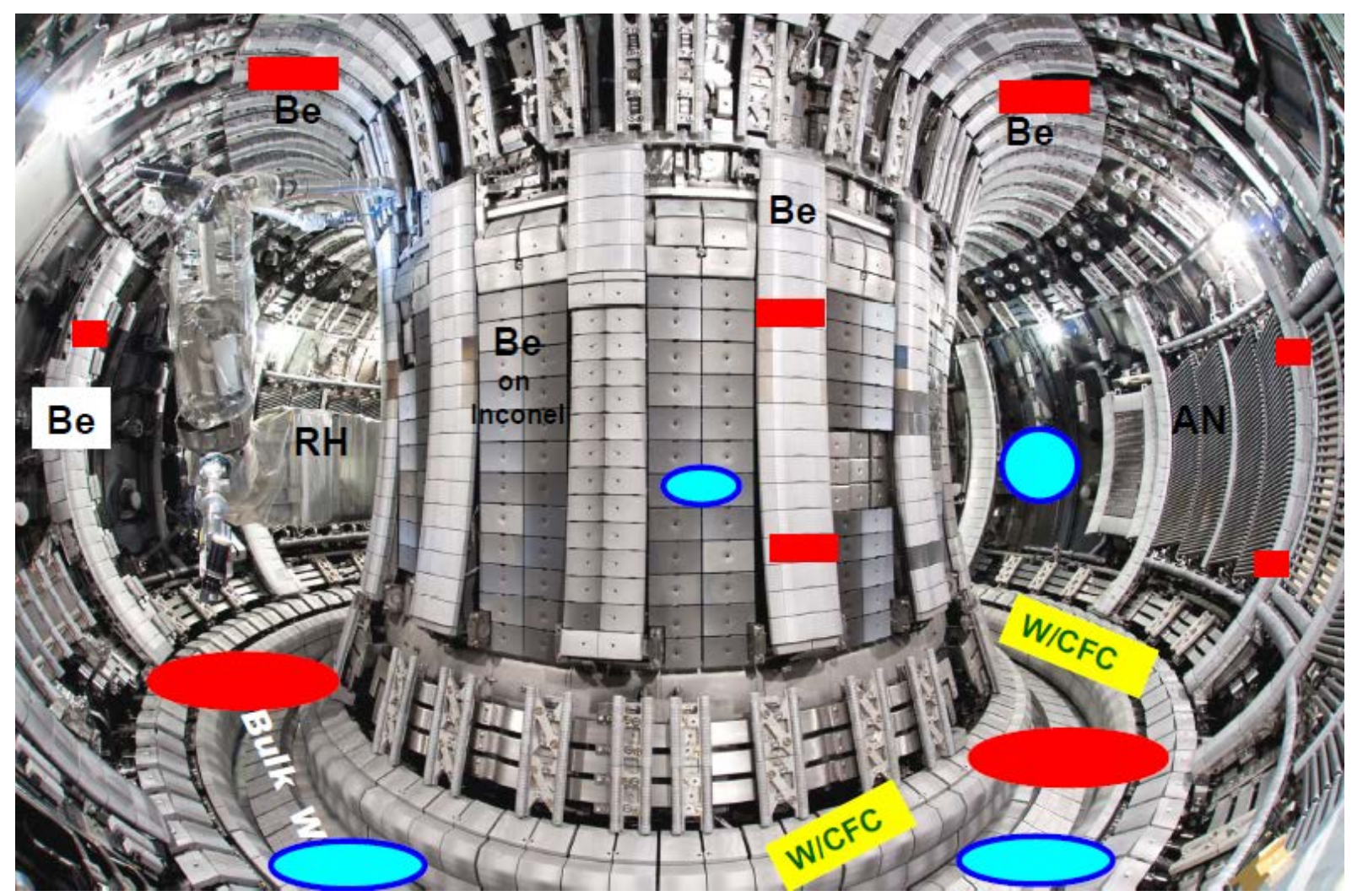




\section{Figure 2}

Operation in the Beryllium Handling Facility at the Culham Science Centre.
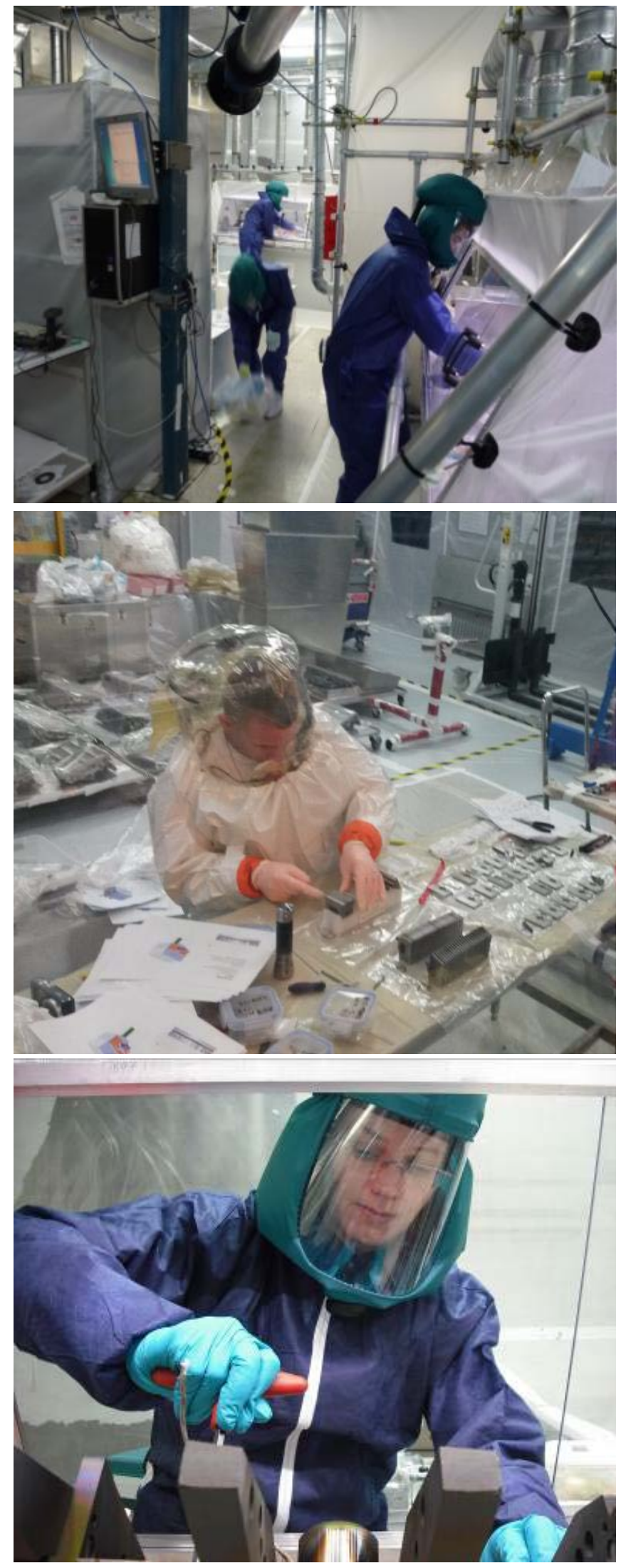


\section{Figure 3}

PFC tiles from JET: (a) W-coated CFC from the JET divertor, Tile 4 bottom of the inner divertor; (b) segment on the castellated Be tile - outer poloidal limiter; (c) Be-coated Inconel inner wall cladding; (d) bulk tungsten divertor Tile 5 with standard and marker lamellae, marked with $S$ and $M$, respectively.
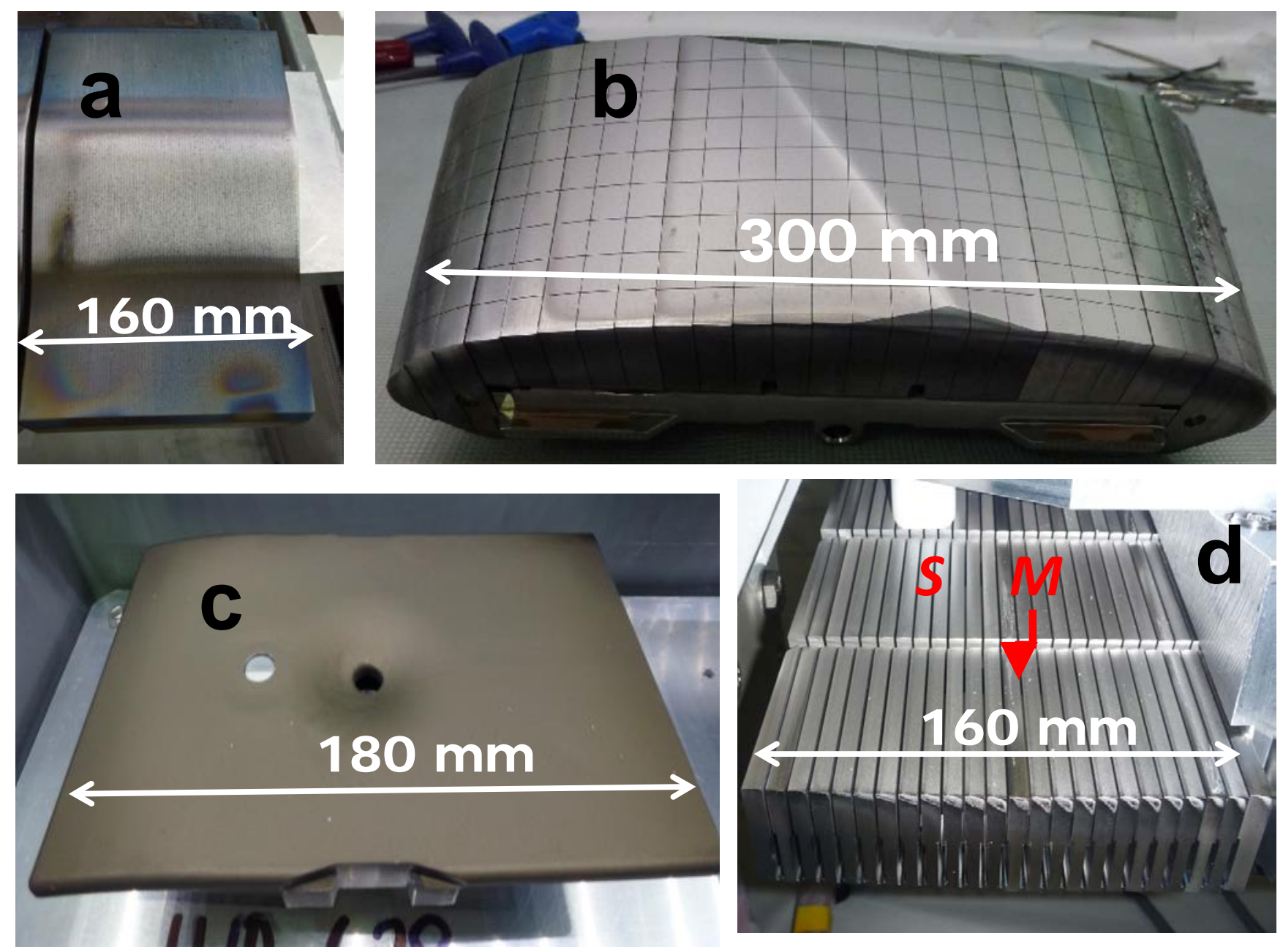


\section{Figure 4}

Beryllium and tritium compatible surface analysis stations at IBA laboratories: (a) Institute of Superior Techniques, Lisbon, Portugal; (b) Max-Planck Institute of Plasma Physics, Garching, Germany.
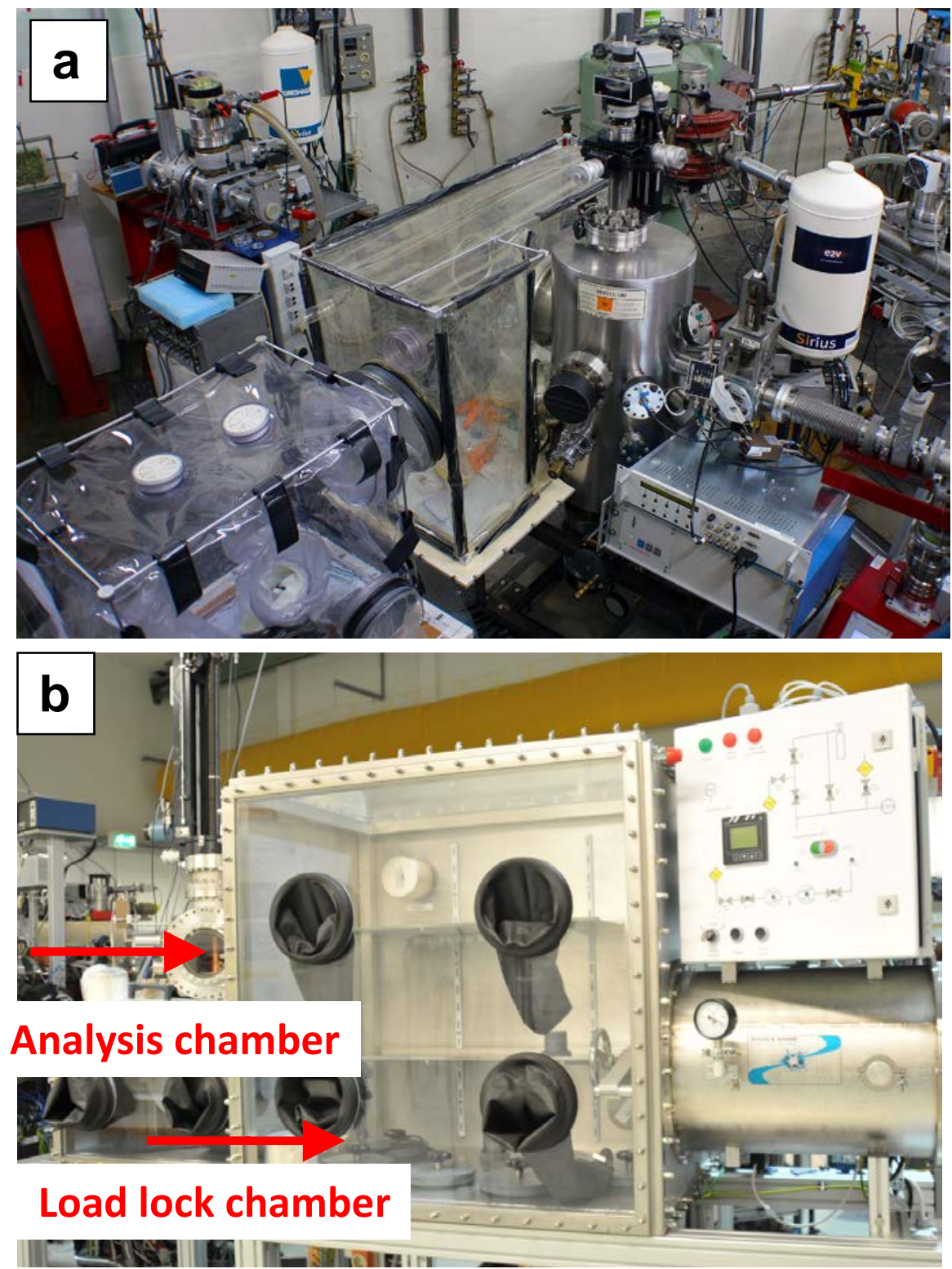


\section{Figure 5}

Beam lines and IBA stations at the $5 \mathrm{MeV}$ Tandem Laboratory, Uppsala University, Sweden.

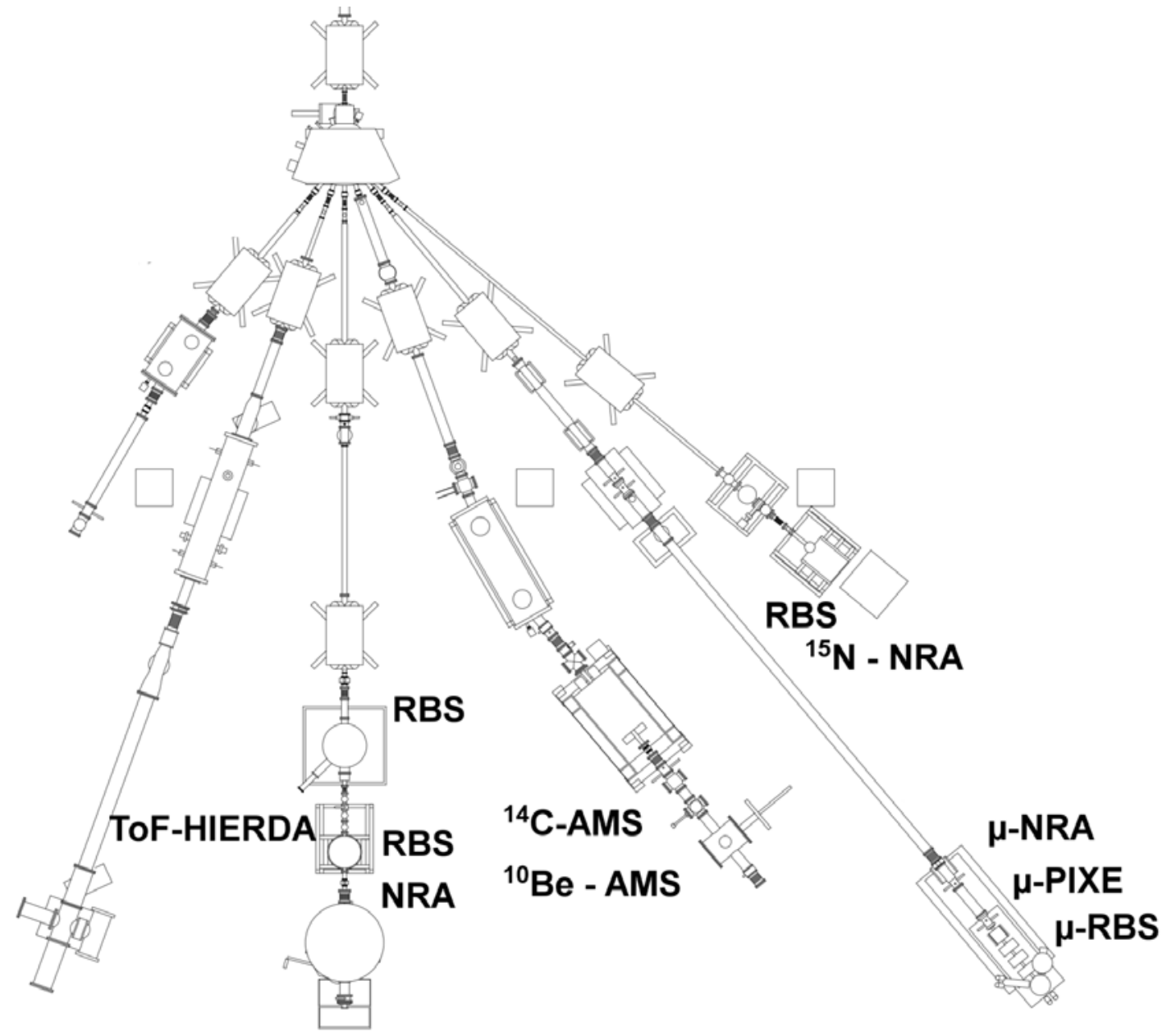




\section{Figure 6}

Cross-section of the JET divertor with the S-coordinate marking the poloidal position of the tiles. Tile 1 is encircled.

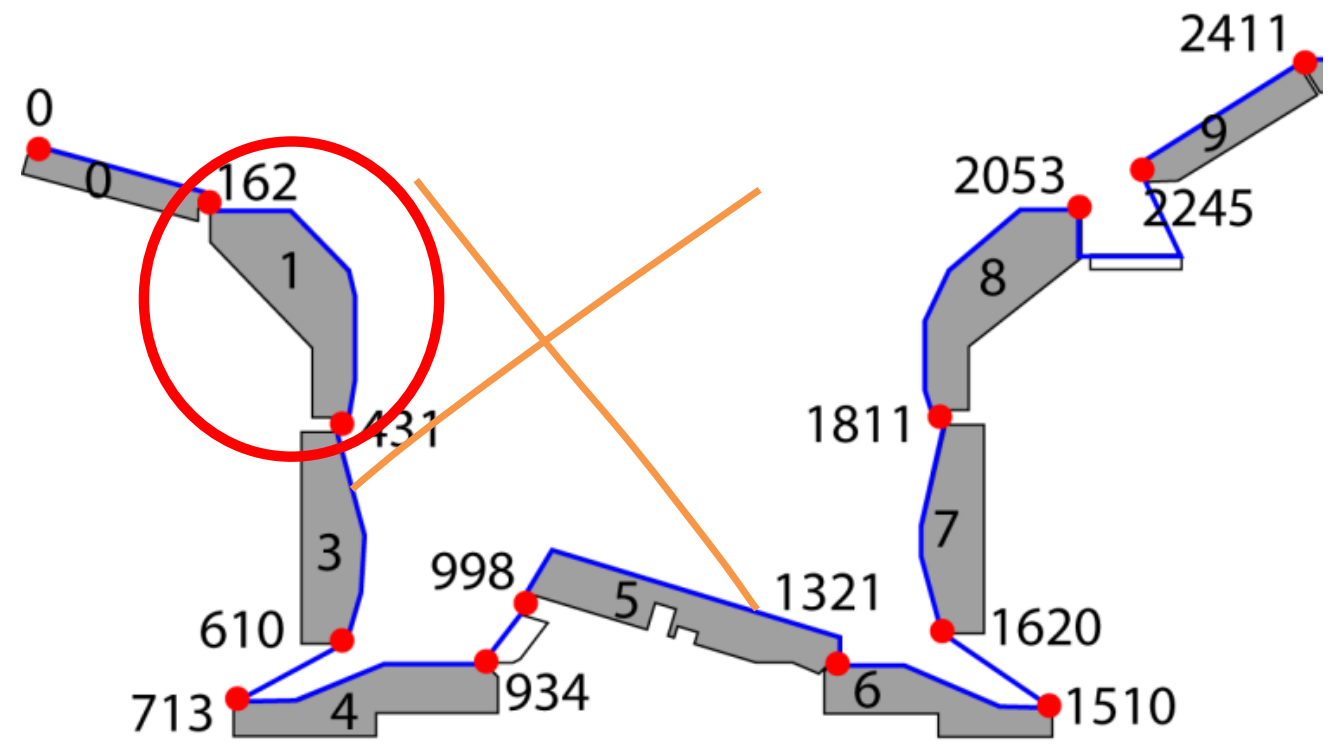




\section{Figure 7}

Erosion-deposition pattern obtained with NRA and RBS for on Tile 1 in the inner divertor of JET-ILW after the campaign 2011-2012.

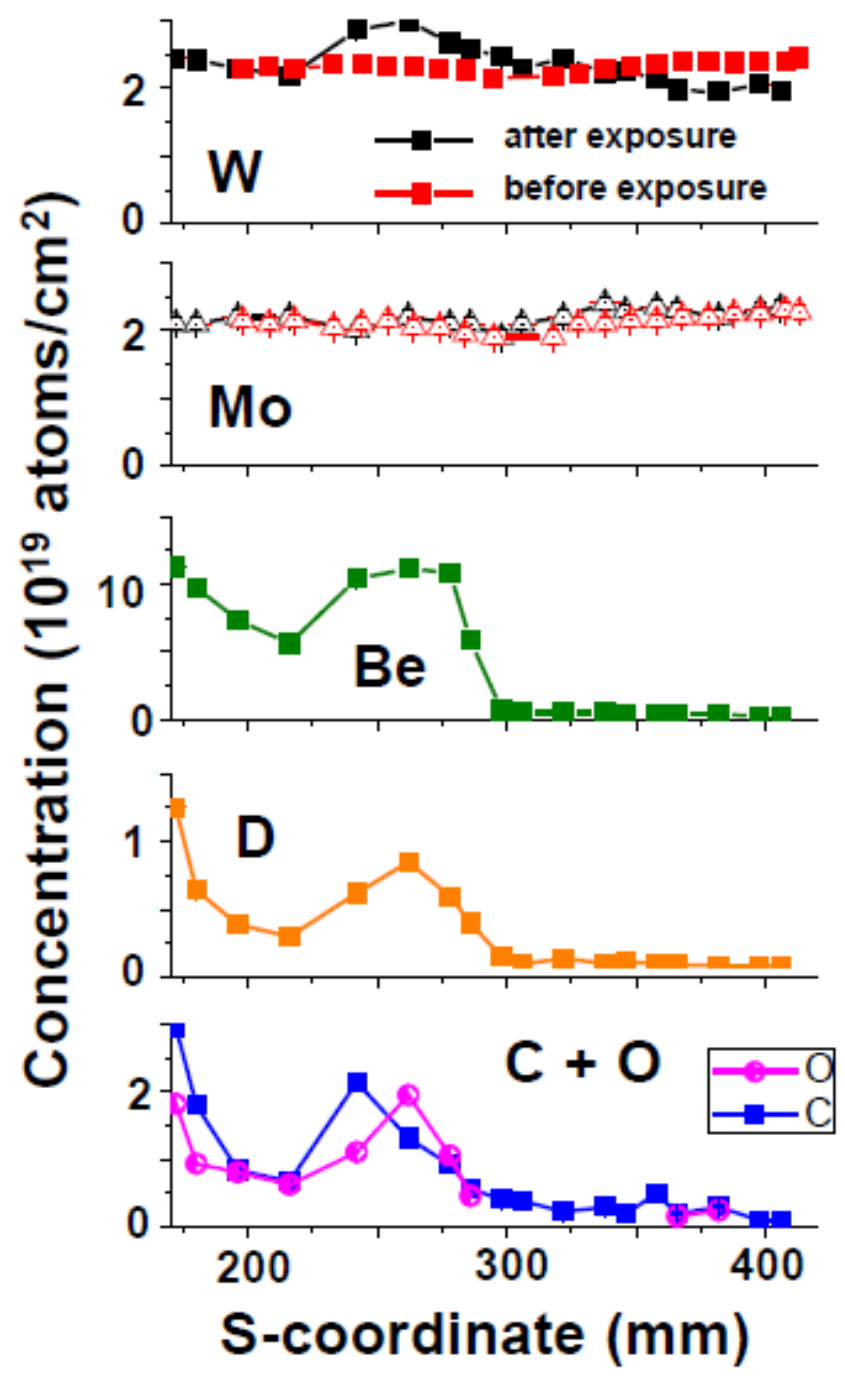




\section{Figure 8}

Castellated beryllium limiters: (a) deposit inside the castellation; (b) micro-beam pattern of deuterium and metals deposition inside the castellation.
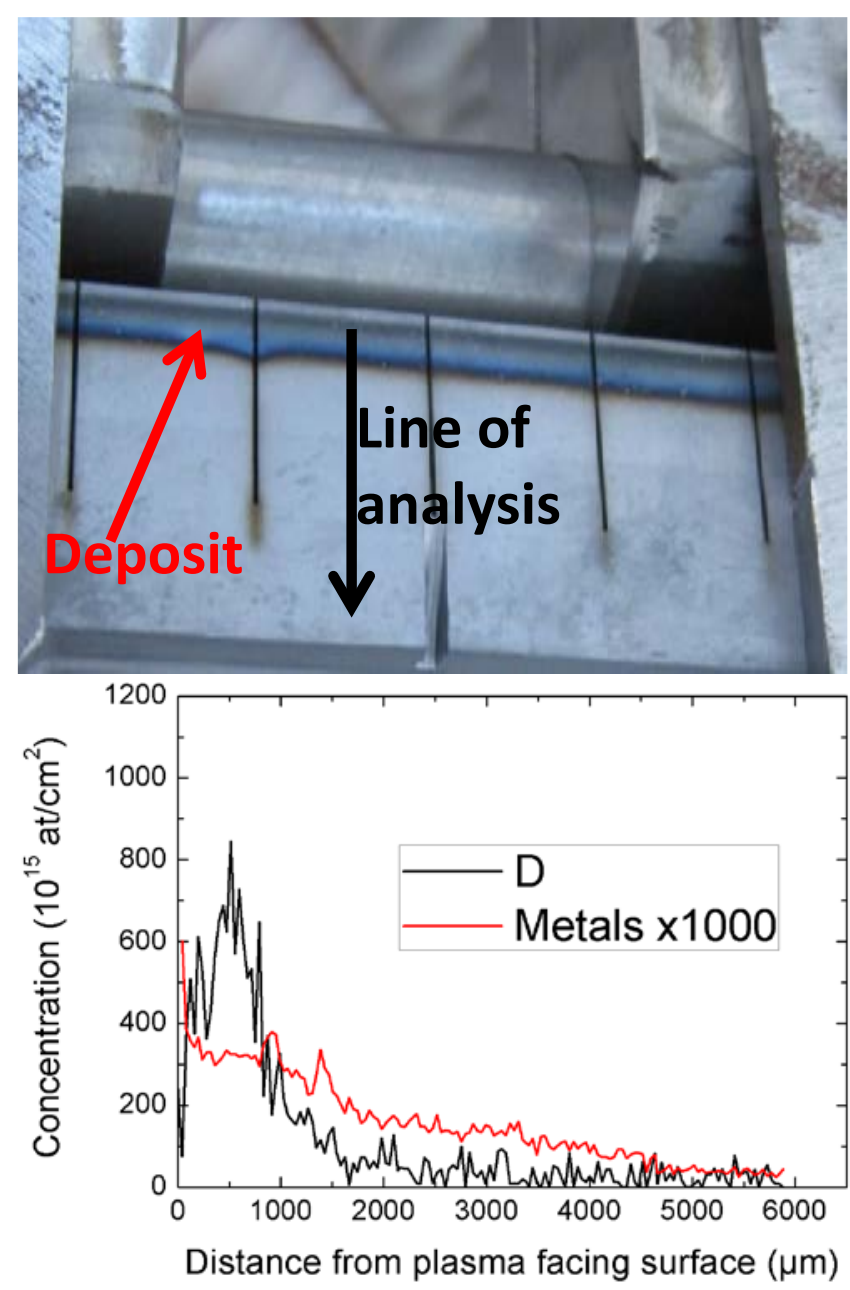


\section{Figure 9}

Surface composition of the mirror exposed in the inner divertor: (a) HIERDA spectrum and

(b) depth profiles of co-deposited elements on the Rh-coated mirror.
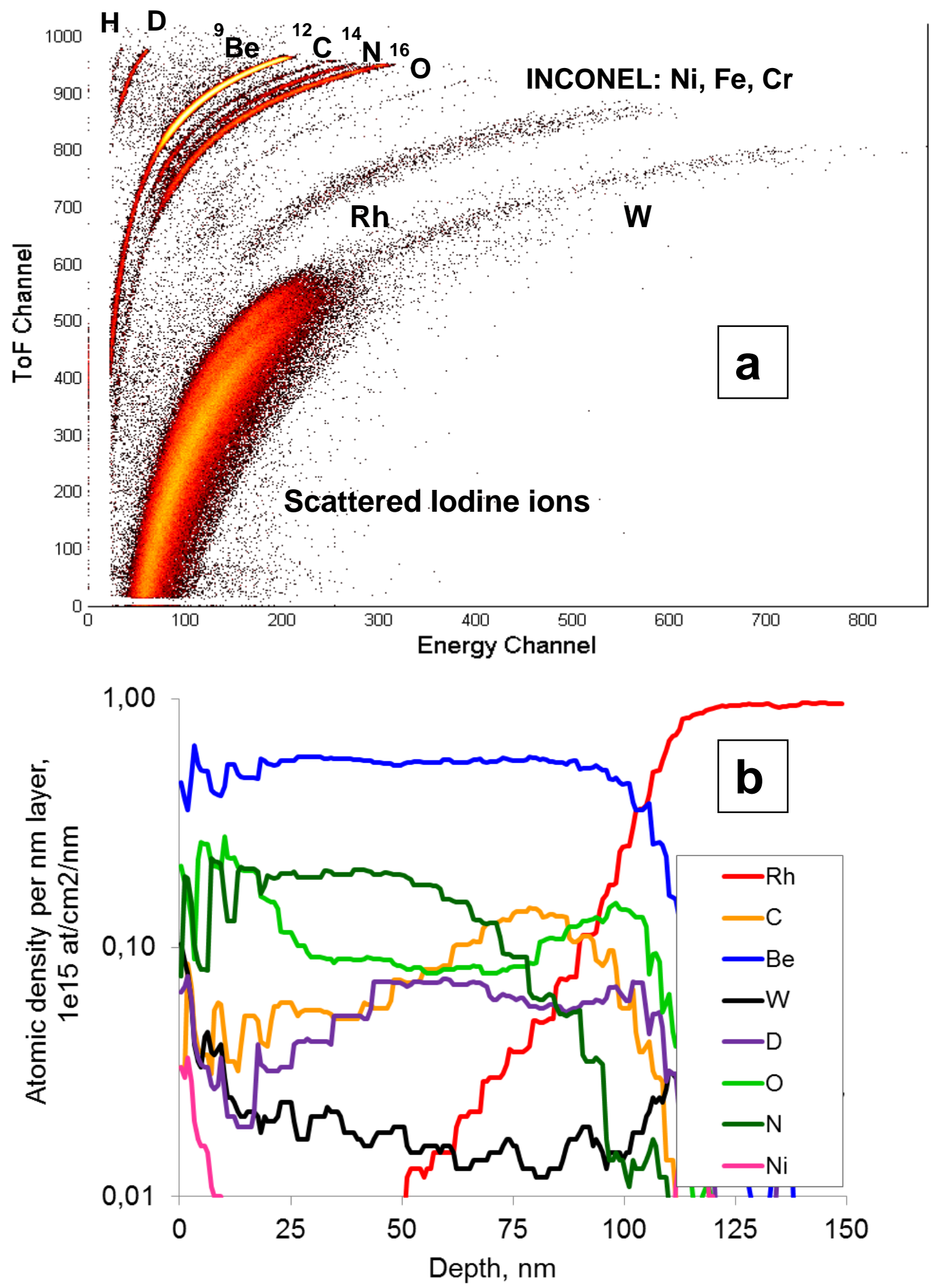